\title{
Patterns of antimicrobial resistance in a surgical intensive care unit of a university hospital in Turkey Aysen Bayram* and Iclal Balci
}

\author{
Address: Gaziantep University Faculty of Medicine, Department of Microbiology and Clinical Microbiology, Gaziantep, Turkey \\ Email: Aysen Bayram* - aysenbayram@hotmail.com; Iclal Balci - balci@gantep.edu.tr \\ * Corresponding author
}

Published: 25 October 2006

BMC Infectious Diseases 2006, 6:155 doi:10.1/86/147/-2334-6-155

This article is available from: http://www.biomedcentral.com/I47I-2334/6/155

(c) 2006 Bayram and Balci; licensee BioMed Central Ltd.

This is an Open Access article distributed under the terms of the Creative Commons Attribution License (http://creativecommons.org/licenses/by/2.0), which permits unrestricted use, distribution, and reproduction in any medium, provided the original work is properly cited.
Received: 16 August 2006

Accepted: 25 October 2006

\begin{abstract}
Background: Several studies have reported higher rates of antimicrobial resistance among isolates from intensive care units than among isolates from general patient-care areas. The aims of this study were to review the pathogens associated with nosocomial infections in a surgical intensive care unit of a university hospital in Turkey and to summarize rates of antimicrobial resistance in the most common pathogens. The survey was conducted over a period of twelve months in a tertiary-care teaching hospital located in the south-eastern part of Turkey, Gaziantep. A total of 87I clinical specimens from 615 adult patients were collected. From 87I clinical specimens 77 I bacterial and fungal isolates were identified.
\end{abstract}

Results: Most commonly isolated microorganisms were: Pseudomonas aeruginosa (20.3\%), Candida species (15\%) and Staphylococcus aureus (12.9\%). Among the Gram-negative microorganisms $P$. aeruginosa were mostly resistant to third-generation cephalosporins (71.3-98.1\%), while Acinetobacter baumannii were resistant in all cases to piperacillin, ceftazidime and ceftriaxone. Isolates of S. aureus were mostly resistant to penicillin, ampicillin, and methicillin (82-95\%), whereas coagulase-negative staphylococci were $98.6 \%$ resistant to methicillin and in all cases resistant to ampicillin and tetracycline.

Conclusion: In order to reduce the emergence and spread of antimicrobial-resistant pathogens in ICUs, monitoring and optimization of antimicrobial use in hospitals are strictly recommended. Therefore local resistance surveillance programs are of most value in developing appropriate therapeutic guidelines for specific infections and patient types.

\section{Background}

Antimicrobial resistance among intensive care unit (ICU) pathogens is generally increasing, but variations do exist among different countries, probably due to individual antimicrobial use patterns. When new medical practices and alternative antimicrobials are introduced, changes in the dominant microbial etiologies may emerge prompting novel empiric selections. Appropriate therapy of ICU infections directed by local resistance data can have signif- icant consequences for both patient and the healthcare system.

Data from National Nosocomial Infections Surveillance (NNIS) shows that from 1988 to 1995 the number of intensive care unit (ICU) beds at the hospitals has increased $17 \%$, whereas total hospital bed capacity decreased slightly [1]. Patients receiving care in ICUs are at high risk for nosocomial infections. The emergence of 
antimicrobial-resistant pathogens in ICUs has made treating these infections very difficult and, in some cases, impossible. Intensive care unit patients are particularly susceptible to nosocomial infections due to underlying illnesses, suppressed immune systems and frequent use of invasive devices.

This study reviews the pathogens associated with nosocomial infections among ICU patients, summarizes rates of antimicrobial resistance in the most common pathogens and provides an overview of strategies to prevent the proliferation of antimicrobial-resistant microorganisms.

\section{Results}

During the study period a total of 871 clinical specimens from 615 adult patients were collected. None of the patients were receiving immunosuppressive therapy. In $771(88.5 \%)$ of cases the isolate recovered by culture was confirmed to be the etiologic agent of a nosocomial infection. The distribution of infections was examined by the major site of infection. Four major infection sites represented $91.8 \%$ of all reported infections; lower respiratory tract infections were most frequent (31.5\%), followed by urinary tract infections $(27.8 \%)$, bloodstream infections $(23.1 \%)$ and surgical site infections $(9.3 \%)$.

The percentages of most frequently isolated microorganisms in ICU were as follows: P. aeruginosa $20.3 \%$, Candida spp. $15 \%$, S. aureus $12.9 \%$, A. baumannii $9.6 \%$, and coagulase-negative staphylococci $8.9 \%$. In lower respiratory tract infections, $P$. aeruginosa $(27.9 \%)$ was the most commonly isolated pathogen, which was followed by $S$. aureus $(13.6 \%)$ and A. baumannii (13.2\%). Fifty-seven percent of reported isolates from the urinary tract were aerobic Gram-negative bacilli, and in $16.3 \%$ of cases Candida spp. were isolated. Bloodstream infections were mostly caused $S$. aureus and coagulase-negative staphylococci with $16.8 \%$ and $16.3 \%$, respectively, whereas $P$. aeruginosa spe- cies $(14.6 \%)$ were also frequently isolated from blood. In surgical site infections S. aureus $(23.6 \%)$ and $P$. aeruginosa $(22.2 \%)$ were the most commonly isolated infectious agents (Table 1).

Each of the pathogens listed on Table 1 has demonstrated antimicrobial resistance to at least one, if not several, of the antimicrobial agents commonly used to treat infections caused by these pathogens. In general, Gram-positive microorganisms such as $S$. aureus and coagulasenegative staphylococci were commonly associated with bloodstream or surgical site infections. Examination of the rates of antimicrobial resistance among these pathogens showed that rates of methicillin-resistant $S$. aureus (MRSA) and methicillin-resistant coagulase-negative staphylococci were $82 \%$ and $98.6 \%$, respectively (Table 2). Antimicrobial resistance profiles of MRSA and MSSA (methicillin-sensitive S. aureus) isolated from infections in ICU were shown in Table 3.

Gram-negative bacilli are frequently associated with nosocomial infections in ICU patients (Table 1). Pseudomonas aeruginosa showed high proportion of resistance against antipseudomonal penicillins (piperacillin 69.4\%, ticarcillin 93\%) and third-generation cephalosporins (ceftazidime $71.3 \%$, cefotaxime $96.2 \%$, ceftriaxone $98.1 \%$ ). Isolates of A. baumannii were in all cases resistant to ceftriaxone and in most cases to aztreonam (94.6\%) and ticarcillin (93.2\%). Although Enterobacter species showed multiple resistance to most antimicrobials tested, they were uniformly susceptible to imipenem and ciprofloxacin. Klebsiella pneumoniae were usually resistant to multiple antimicrobials and hydrolized third-generation cephalosporins and aztreonam (72-88\%) (Table 4).

\section{Discussion}

A number of factors contribute to the emergence of antimicrobial resistance in ICUs including the severity of

Table I: Microorganisms reported from intensive care unit according to the site of infection.

\begin{tabular}{|c|c|c|c|c|c|c|c|c|c|c|}
\hline \multirow[t]{2}{*}{ Microorganism } & \multicolumn{2}{|c|}{ Respiratory Tract } & \multicolumn{2}{|c|}{ Urinary Tract } & \multicolumn{2}{|c|}{ Bloodstream } & \multicolumn{2}{|c|}{ Surgical Site } & \multicolumn{2}{|c|}{ Other Sites' } \\
\hline & $\mathrm{n}$ & $\%$ & $\mathrm{n}$ & $\%$ & $\mathrm{n}$ & $\%$ & $\mathrm{n}$ & $\%$ & $\mathrm{n}$ & $\%$ \\
\hline Pseudomonas aeruginosa & 68 & 27.9 & 30 & 13.9 & 26 & 14.6 & 16 & 22.2 & 17 & 26.9 \\
\hline Staphylococcus aureus & 33 & 13.6 & 9 & 4.2 & 30 & 16.8 & 17 & 23.6 & II & 17.5 \\
\hline Acinetobacter baumannii & 32 & 13.2 & 20 & 9.3 & II & 6.2 & 6 & 8.3 & 5 & 7.9 \\
\hline Candida spp. & 31 & 12.8 & 35 & 16.3 & 30 & 16.8 & 10 & 13.9 & 10 & 15.8 \\
\hline $\mathrm{CN}^{2}$ - staphylococci & 16 & 6.6 & 10 & 4.6 & 29 & 16.3 & 10 & 13.9 & 4 & 6.4 \\
\hline Klebsiella pneumoniae & II & 4.5 & 9 & 4.2 & 2 & I.I & 2 & 2.8 & I & 1.6 \\
\hline Enterobacter spp. & 10 & 4.1 & 13 & 6.1 & 6 & 3.4 & 2 & 2.8 & I & 1.6 \\
\hline Enterococcus spp. & 6 & 2.5 & 22 & 10.2 & 13 & 7.3 & I & 1.4 & 2 & 3.2 \\
\hline Escherichia coli & 3 & 1.2 & 27 & 12.6 & 4 & 2.3 & 3 & 4.2 & I & 1.6 \\
\hline Others & 33 & 13.6 & 40 & 18.6 & 27 & 15.2 & 5 & 6.9 & II & 17.5 \\
\hline Total & 243 & 100 & 215 & 100 & 178 & 100 & 72 & 100 & 63 & 100 \\
\hline
\end{tabular}

I Cerebrospinal fluid, pericardial fluid, peritonal fluid, synovial fluid, biopsy, oral swab, rectal and anal swabs

2 Coagulase-negative 
Table 2: Antimicrobial susceptibilities of Gram-positive microorganisms isolated from infections in ICU.

\begin{tabular}{lccc}
\hline & \multicolumn{2}{c}{ Percentage (\%) of isolates resistant to indicated drug by broth microdilution } \\
\hline Antimicrobial & $\begin{array}{c}\text { S. aureus } \\
n=100\end{array}$ & $\begin{array}{c}\text { CN' }- \text { staphylococci } \\
n=69\end{array}$ & $\begin{array}{c}\text { Enterococcus spp. } \\
n=44\end{array}$ \\
\hline Penicillin G & $95 \%$ & $98.6 \%$ & $84.1 \%$ \\
Ampicillin & $95 \%$ & $100 \%$ & $77.3 \%$ \\
Amoxicillin/clavulanate & $81 \%$ & $88.4 \%$ & $77.3 \%$ \\
Methicillin & $82 \%$ & $98.6 \%$ & $50 \%$ \\
Vancomycin & $0 \%$ & $0 \%$ & $0 \%$ \\
Clindamycin & $72 \%$ & $66.7 \%$ & $86.4 \%$ \\
Erythromycin & $86 \%$ & $86.9 \%$ & $86.4 \%$ \\
TMP/SMX & $39 \%$ & $100 \%$ & $75 \%$ \\
Ciprofloxacin & $78 \%$ & $37.7 \%$ & $81.8 \%$ \\
Tetracycline & $86 \%$ & $100 \%$ & $84.1 \%$ \\
\hline
\end{tabular}

I Coagulase-negative

2 Trimethoprim/sulfamethoxazol

patient illness, predisposition to nosocomial infections, cross-transmission of pathogens characteristic of critical care areas within the hospital, compromised membrane and skin barriers following the use of invasive devices, extended length of hospital stay, and the widespread use of prophylactic and therapeutic anti-infective agents $[2,3]$.

The types of organisms that have emerged as most problematic for patients within the ICU include the members of the family Enterobacteriaceae, non-fermenters (P. aeruginosa and Acinetobacter spp.) oxacillin-resistant $S$. aureus and vancomycin-resistant enterococci. All of these resistance profiles have been documented in other regional and global ICU surveillance studies including Project Intensive Care Antimicrobial Resistance Epidemiology (ICARE, 1994-2000), the Meropenem Yearly Susceptibility Test Information Collection Program (MYSTIC, 1997-2000), the ICU Surveillance Study (ISS, 1990-1993, 1994-2000) and the SENTRY Program (Europe, 1997-1998) [3-8].
The rank order of pathogens recovered in SENTRY Antimicrobial Surveillance Program was S. aureus (24.1\%), P. aeruginosa (12.2\%), E. coli (10.1\%), Klebsiella spp. (8.9\%), Enterococcus spp. (7.2\%), coagulase-negative staphylococci $(7 \%)$ and Enterobacter spp. (7\%) (5). In the MYSTIC Study, P. aeruginosa (33\%) was the most frequent isolate, followed by A. baumannii (17.1\%), K. pneumoniae (12.1\%), E. coli $(10.5 \%)$ and E. cloacae $(7.9 \%)$ (GarciaRodriguez and Jones, 2002). In this study $P$. aeruginosa $(20.3 \%)$ was the most commonly isolated pathogen in ICU, which was followed by Candida spp. (15\%), S. aureus (12.9\%), A. baumannii (9.6\%), and coagulase-negative staphylococci $(8.9 \%)$.

Patients in the ICU are more likely than others to be colonized or infected with an antimicrobial-resistant pathogen, therefore the rates of resistance are significantly higher in patients cared for in the ICU than in non-ICU patients [9-14].

Table 3: Antimicrobial resistances of MRSA and MSSA isolated from infections in ICU.

\begin{tabular}{|c|c|c|}
\hline \multicolumn{3}{|c|}{ Percentage $(\%)$ of isolates resistant to antimicrobial by broth microdilution } \\
\hline Antimicrobial & $\begin{array}{c}\text { MRSA }^{\prime} \\
n=82\end{array}$ & $\begin{array}{l}M^{M_{S S A}}{ }^{2} \\
n=18\end{array}$ \\
\hline Vancomycin & $0 \%$ & $0 \%$ \\
\hline Clindamycin & $73.2 \%$ & $66.7 \%$ \\
\hline Erythromycin & $90.2 \%$ & $66.7 \%$ \\
\hline $\mathrm{TMP} / \mathrm{SM} \mathrm{X}^{3}$ & $42.7 \%$ & $22.2 \%$ \\
\hline Ciprofloxacin & $79.3 \%$ & $72.2 \%$ \\
\hline Tetracycline & $87.8 \%$ & $77.7 \%$ \\
\hline
\end{tabular}

I Methicillin-resistant S. aureus

2 Methicillin-susceptible S. aureus

3 Trimethoprim/sulfamethoxazol 
Table 4: Antimicrobial susceptibilities of Gram-negative microorganisms isolated from infections in ICU.

\begin{tabular}{|c|c|c|c|c|c|}
\hline \multicolumn{6}{|c|}{ Percentage $(\%)$ of isolates resistant to antimicrobial by broth microdilution } \\
\hline Antimicrobial & $\begin{array}{l}\text { P. aeruginosa } \\
\mathrm{n}=157\end{array}$ & $\begin{array}{c}\text { A. baumannii } \\
\mathrm{n}=74\end{array}$ & $\begin{array}{l}\text { Enterobacter spp } \\
\quad \mathrm{n}=32\end{array}$ & $\begin{array}{c}\text { K. pneumoniae } \\
n=25\end{array}$ & $\begin{array}{c}\text { E. coli } \\
\mathrm{n}=38\end{array}$ \\
\hline Amikacin & $29.9 \%$ & $71.6 \%$ & $59.4 \%$ & $16 \%$ & $18.4 \%$ \\
\hline Azteronam & $77.1 \%$ & $94.6 \%$ & $81.2 \%$ & $88 \%$ & $86.8 \%$ \\
\hline Piperacillin & $69.4 \%$ & $100 \%$ & $71.8 \%$ & $76 \%$ & $68.4 \%$ \\
\hline Ticarcillin & $93 \%$ & $93.2 \%$ & $81.2 \%$ & $64 \%$ & $68.4 \%$ \\
\hline Ceftriaxone & $98.1 \%$ & $100 \%$ & $59.4 \%$ & $84 \%$ & $84.2 \%$ \\
\hline Cefotaxime & $96.2 \%$ & $100 \%$ & $59.4 \%$ & $84 \%$ & $84.2 \%$ \\
\hline Ceftazidime & $71.3 \%$ & $100 \%$ & $75 \%$ & $88 \%$ & $86.8 \%$ \\
\hline Ciprofloxacin & $59.2 \%$ & $56.7 \%$ & $0 \%$ & $20 \%$ & $39.5 \%$ \\
\hline Imipenem & $26.1 \%$ & $63.5 \%$ & $0 \%$ & $12 \%$ & $13.1 \%$ \\
\hline Cefoperazone & $93 \%$ & $100 \%$ & $62.5 \%$ & $72 \%$ & $86.8 \%$ \\
\hline Gentamicin & $48.4 \%$ & $85.1 \%$ & $81.2 \%$ & $80 \%$ & $78.9 \%$ \\
\hline
\end{tabular}

Examination of Gram-positive microorganisms, such as $S$. aureus and coagulase-negative staphylococci shows that rates of methicillin-resistant isolates in ICU have increased steadily over the past decade [13-15]. In our study $82 \%$ of $S$. aureus strains and $98.6 \%$ of coagulasenegative staphylococci were resistant to methicillin.

Gram-negative bacilli are frequently associated with nosocomial infections in ICUs. Data from a multicenter Intensive Care Unit Surveillance Study (ISS) in the United States demonstrated that resistance to antipseudomonal agents among ICU isolates of $P$. aeruginosa, especially fluoroquinolones, was increasing [16]. The isolates of $P$. aeruginosa in this study were resistant 71.4 to $98 \%$ to third generation cephalosporins, and 69.4 to $93 \%$ to antipseudomonal penicillins. The relatively high susceptibility of Gram-negative bacilli to fluoroquinolones in this study can be attributed to antimicrobial prescribing protocol used in our ICU, which is preferably directed to broadspectrum antibiotics.

In recent years Acinetobacter spp. have emerged as important pathogens of ICUs, most of them being resistant to ampicillin, carbenicillin, cefotaxime, chloramphenicol, and gentamicin $[17,18]$. In our study, all A. baumannii isolates were resistant to third generation cephalosporins, and most of them were resistant to aztreonam, ticarcillin, and gentamicin with $94.6 \%, 93.2 \%$, and $85.1 \%$, respectively.

Enterobacter species are resistant to first-generation cephalosporins and develop antibiotic resistance readily to second- and third-generation cephalosporins owing to an inducible chromosomally encoded cephalosporinase. Emergence of this form of resistance is seen frequently, when infection due to these organisms, particularly Enterobacter cloacae, are treated with broad-spectrum cephalosporins [19]. Pfaller et al. [20] reported that out of 230 Enterobacter isolates 35-50\% were resistant to ceftazidime and piperacillin. In this study the resistance rates of Enterobacter strains to third generation cephalosporins were between 59.4-75\%, whereas higher rates were recorded to aztreonam and gentamicin (both $81.2 \%$ ).

Another type of commonly seen antimicrobial-resistant pathogen encountered among ICU patients is Klebsiella pneumoniae, which is producing extended-spectrum betalactamases (ESBLs). Our isolates of $K$. pneumoniae showed high resistance to broad-spectrum cephalosporins and aztreonam (72-88\% and $88 \%$, respectively).

Many studies have demonstrated that the development of antimicrobial resistance at hospital level is strongly correlated with the use of the relevant antimicrobial [21]. Data from project ICARE showed that use was significantly higher among ICU patients than non-ICU patients for third-generation cephalosporins combined, vancomycin, anti-pseudomonal penicillin, intravenous fluoroquinolones and imipenem [22]. This study supports that for each of the antimicrobial agent used at higher rates in ICU areas, there was a correspondingly higher rate of the respective resistant pathogen among ICU patients.

\section{Conclusion}

In order to prevent the emergence and spread of antimicrobial resistant pathogens in ICU, the pattern of antimicrobial use has to be determined. A multidisciplinary approach is required to succeed in combating the problem. Hospitals should monitor antimicrobial use to determine whether specific ICUs or the entire hospital is overusing antimicrobials. These data could be used, in conjunction with other related studies, to properly interpret significant resistance patterns and choose the most appropriate antimicrobial regimens for empirical therapy. 


\section{Methods}

Data were collected from adult patients hospitalized in the surgical ICU of the Medical Faculty Hospital during one year period between January and December in 2001. Standard Centers for Disease Control and Prevention/ NNIS definitions of infection were used [23]. All patients in the ICU were monitored for nosocomial infection at all body sites for a period of at least one month. Nosocomial infections were analyzed by infection site and pathogen type. Infections were considered ICU-associated if they developed in the ICU within 48 hours of admission or within 48 hours of discharge from the ICU. Bloodstream infection was reported if the patient had either two or more positive cultures drawn on separate occasions, or one positive blood culture and treatment was instituted. The data collected on each infection included the date, site of infection, age and gender of the patient. Written informed consent was obtained from all subjects prior to their inclusion in the study.

Lower respiratory tract specimens included bronchoalveolar lavage, transtracheal aspiration, and pleural fluid. Urinary tract specimens included urine and aspiration from the urinary catheter. Other types of specimens obtained from the patients were; swabs from surgical wounds, cerebrospinal fluid, pericardial fluid, peritonal fluid, synovial fluid, biopsy material, oral swab, rectal and anal swabs. All specimens were collected at the bed site, transferred to the laboratory immediately and were inoculated on proper culture media within two hours. Clinical specimens were inoculated onto 5\% sheep blood agar, eosinemethylene-blue agar, Sabouraud's dextrose agar, and except the urine specimens, onto chocolate agar (Oxoid, Basingstoke, United Kingdom). Plates were incubated at $37^{\circ} \mathrm{C}$ in $5 \% \mathrm{CO}_{2}$ for $18-24$ hours. Methods used for confirmation of identification included examination of colonial morphology and haemolytic characteristics on appropriate agar media, Gram stain, rapid tests (catalase, oxidase, coagulase, bile solubility, spot indole, latex agglutination) and use of an automated identification system, VITEK (bioMérieux, Marcy-1'Etoile, France), which is a microbroth dilution method with two wells across predetermined breakpoints.

Penicillin G, ampicillin, amoxicillin/clavulanate, methicillin, vancomycin, clindamycin, erythromycin, trimethoprim/sulfamethoxazol, ciprofloxacin, and tetracycline were used for antimicrobnial susceptibility testing. Susceptibility tests were performed with a commercial broth microdilution method (VITEK; bioMérieux, Marcy1'Etoile, France) according to the manufacturers' guideline recommendations and interpretative criteria. Colonies from 18-24 hours old culture medium were used to inoculate the microdilution plates. Quality control for testing by VITEK was performed before each new lot of cards was used. Antimicrobial susceptibilities of the control microorganisms (S. aureus ATCC 29213, P. aeruginosa ATCC 27853 and Enterococcus faecalis ATCC 29212) were performed according to the instructions of CLSI (previously NCCLS) [24].

All data were stored and analysed using Microsoft Access and Excel. Statistical analysis was performed using the chisquared test for independence and Fisher's exact test where appropriate. All statisticss were computed using Scientific Package for Social Sciences (SPSS) software (version 11.0; SPSS Inc., Chicago, IL).

\section{Authors' contributions}

$\mathrm{AB}$ carried out the collection of clinical samples from patients, cultured and identified pathogenic microorganisms from those specimens and perfomed antimicrobial susceptibility tests of the study strains. She also designed the study and performed acquisition, analysis and interpretation of data. IB conceived of the study, and participated in its design and coordination and helped to draft the manuscript. Both authors read and approved the final version of the manuscript.

\section{Acknowledgements}

The authors thank Fitzroy A Orrett and Philip J Turner for editorial assistance.

\section{References}

I. Archibald L, Phillips L, Monnet D, McGowan JE Jr, Tenover F, Gaynes $R$ : Antimicrobial resistance in isolates from inpatients and outpatients in the United States: increasing importance of the intensive care unit. Clin Infect Dis 1997, 24:2 II-2I 5.

2. Weinstein R: Controlling antimicrobial resistance in hospitals: infection control and use of antibiotics. Emerg Infect Dis 200I, 7:|88-191.

3. Streit JM, Jones RN, Sader HS, Fritsche TR: Assessment of pathogen occurrences and resistance profiles among infected patients in the intensive care unit: report from the SENTRY Antimicrobial Surveillance Program (North America, 200I). Int J Antimicrob Agents 2004, 24: I I I- I I8.

4. Fridkin SK, Hill HA, Volkova NV, Edwards JR, Lawton RM, Gaynes RR, McGowan JE Jr: Temporal changes in prevalence of antimicrobial resistance in $\mathbf{2 3}$ US hospitals. Emerg Infect Dis 2002, 8:697-70l.

5. Garcia-Rodriguez JA, The MYSTIC Programme Study Group, Jones $\mathrm{RN}$ : Antimicrobial resistance in Gram-negative isolates from European intensive care units: data from the Meropenem Yearly Susceptibility Test Information Collection (MYSTIC) Programme. J Chemother 2002, I 4:25-32.

6. Fridkin SK, Edwards JR, Courval JM, Hill H, Tenover FC, Lawton R, Gaynes RP, McGowan JE Jr: The effect of vancomycin and thirdgeneration cephalosporins on prevalence of vancomycinresistant enterococci in 126 US adult intensive care units. Ann Intern Med 200I, I35:I75-I83.

7. Fluit AC, Verhoef J, The European SENTRY Participants, Schmitz FJ: Frequency of isolation and antimicrobial resistance of Gramnegative and Gram-positive bacteria from patients in intensive care units of 25 European university hospitals participating in the European arm of the SENTRY Antimicrobial Surveillance Program 1997-1998. Eur J Clin Microbiol Infect Dis 2001, 20:617-625.

8. Neuhauser MM, Weinstein RA, Rydman R, Danziger LH, Karam G, Quinn JP: Antibiotic resistance among Gram-negative bacilli in US intensive care units. JAMA 2003, 289:885-888. 
9. Mendes C, Oplustil C, Sakagami E, Turner P, Kiffer C, The MYSTIC Brazil Group: Antimicrobial Susceptibility in Intensive Care Units: MYSTIC Program Brazil 2002. Brazilian J Infect Dis 2005, 9:44-5I.

10. Mendes C, Turner PJ: Unit differences in pathogen occurrence arising from the MYSTIC program European database (1997-2000). Diagn Microbiol Infect Dis 200I, 41:19I-196.

II. Pfaller MA, Jones RN, Biedenbach DJ: Antimicrobial resistance trends in medical centers using carbapenems: report of 1999 and 2000 results from the MYSTIC program (USA). Diagn Microbiol Infect Dis 200I, 4I: I77-I82.

12. Diekema DJ, Pfaller MA, Jones RN, Doern GV, Winokur PL, Gales AC, Sader HS, Kugler K, Beach M: Survey of bloodstream infection due to Gram-negative bacilli: frequency of occurrence and antimicrobial susceptibility of isolates collected in the United States, Canada and Latin America for the SENTRY Antimicrobial Surveillance Program 1997. Clin Infect Dis 1997, 29:595-607.

13. Diekema DJ, Pfaller MA, Jones RN, Doern GV, Kugler K, Beach ML, Sader HS: Trends in antimicrobial susceptibility of bacterial pathogens isolated from patients with bloodstream infection in the USA, Canada and Latin America. SENTRY Participants Group. Int J Antimicrob Agents 2000, 13:257-27I.

14. Fridkin SK, Gaynes RP: Antimicrobial resistance in intensive care units. Clinics in Chest Medicine 1999, 20:303-316.

15. Aubry-Damon H, Courvalin P: Bacterial Resistance to Antimicrobial Agents: Selected Problems in France, 1996 to 1998. Emerg Infect Dis 1999, 5:3 I5-320.

16. Friedland I, Gallagher G, King T, Woods GL: Antimicrobial susceptibility patterns in Pseudomonas aeruginosa: data from a multicenter Intensive Care Unit Surveillance Study (ISS) in the United States. J Chemother 2004, 16:437-44I.

17. Lortholary O, Fagon JY, Hoi AB, Slama MA, Pierre J, Giral P, Rosenzweig R, Gutmann L, Safar M, Acar J: Nosocomial acquisition of multi-resistant Acinetobacter baumannii: Risk factors and prognosis. Clin Infect Dis 1995, 20:790-796.

18. Seifert H, Baginski R, Schulze A, Pulverer G: Antimicrobial susceptibility of Acinetobacter species. Antimicrob Agents Chemother 1993, 37:750-753.

19. Eisenstein BI, Zaleznik DF: Enterobacteriaceae. In Principles and Practice of Infectious Diseases Edited by: Mandell GL, Bennett JE, Dolin R. Churchill Livingstone; 2000.

20. Pfaller MA, Jones RN, Marshall SA, Coffman SL, Hollis RJ, Edmond MB, Wenzel RP: Inducible amp $C$ beta-lactamase producing gramnegative bacilli from blood stream infections: Frequency, antimicrobial susceptibility, and molecular epidemiology in a national surveillance program (SCOPE). Diagn Microbiol Infect Dis 1997, 28:21 I-219.

21. Shlaes DM, Gerding DN, John JF Jr, Craig WA, Bornstein DL, Duncan RA, Eckman MR, Farrer WE, Greene WH, Lorian V, Levy S, McGowan JE Jr, Paul SM, Ruskin J, Tenover FC, Watanakunakorn C: Society for Healthcare Epidemiology of America and Infectious Diseases Society of America Joint Committee on the Prevention of Antimicrobial Resistance: guidelines for the prevention of antimicrobial resistance in hospitals. Infect Control Hosp Epidemiol 1997, | 8:275-29|.

22. Fridkin SK, Steward CD, Edwards JR, Pryor ER, McGowan JE Jr, Archibald LK, Gaynes RP, Tenover FC: Surveillance of antimicrobial use and antimicrobial resistance in US hospital: project ICARE Phase 2. Project Intensive Care Antimicrobial Resistance Epidemiology (ICARE) hospitals. Clin Infect Dis 1999, 29:245-252

23. Richards MJ, Edwards JR, Culver DH, Gaynes RP: Nosocomial infections in medical intensive care units in the United States. National Nosocomial Infections Surveillance System. Crit Care Med 1999, 27:887-892.

24. NCCLS: Performance Standards for Antimicrobial Susceptibility Testing: eleventh informational supplement MIO0S13. NCCLS Wayne Pa 2003.

\section{Pre-publication history}

The pre-publication history for this paper can be accessed here: http://www.biomedcentral.com/1471-2334/6/155/pre pub
Publish with Bio Med Central and every scientist can read your work free of charge

"BioMed Central will be the most significant development for disseminating the results of biomedical research in our lifetime. "

Sir Paul Nurse, Cancer Research UK

Your research papers will be:

- available free of charge to the entire biomedical community

- peer reviewed and published immediately upon acceptance

- cited in PubMed and archived on PubMed Central

- yours - you keep the copyright
BioMedcentral 